\title{
Supporting Information for \\ Ionomers from Step-growth Polymerization: \\ Highly Ordered Ionic Aggregates and Ion Conduction
}

\author{
Lu Yan ${ }^{\dagger}$, Lauren Hoang ${ }^{\S}$, and Karen I. Winey ${ }^{*}, \dagger \S$ \\ ${ }^{\dagger}$ Department of Chemical and Biomolecular Engineering, University of Pennsylvania, Philadelphia, \\ Pennsylvania, United States \\ ${ }^{\S}$ Department of Materials Science and Engineering, University of Pennsylvania, Philadelphia, \\ Pennsylvania, United States \\ *Corresponding author.Email: winey@seas.upenn.edu
}

\section{Table of Contents}

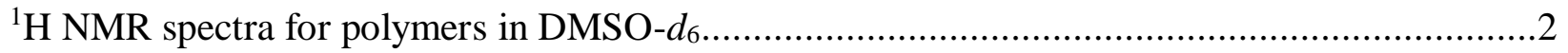

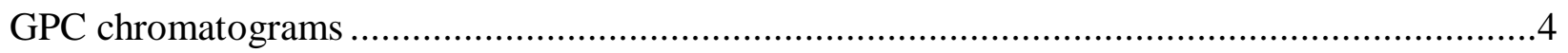

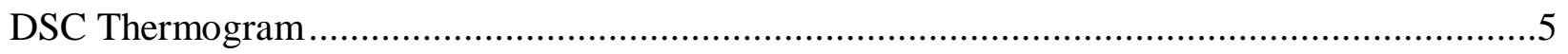

Fitting of the X-ray scattering profiles ......................................................................... 6

Electrochemical Impedance Spectroscopy (EIS) data ..................................................

Fitting parameters for ionic conductivity data ...................................................... 10

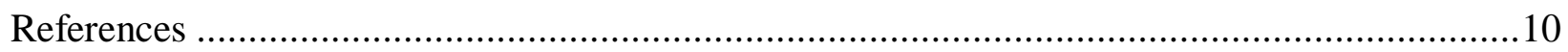




\section{${ }^{1} \mathrm{H}$ NMR spectra for polymers in DMSO- $d_{6}$}

The chemical structures of synthesized polymers were characterized by ${ }^{1} \mathrm{H}$ NMR. The peaks at $0 \mathrm{ppm}$, $2.5 \mathrm{ppm}$, and $3.3 \mathrm{ppm}$ correspond to TMS, DMSO, and water traces in DMSO. The integration of proton peaks showed good agreement with the number of hydrogens in the backbone. The chemical shift of protons at $\mathrm{H}-4, \mathrm{H}-5, \mathrm{H} 4$ ', H5' or H4", H5" position partially overlap with the protons from DMSO, and thus the total number of protons obtained from integration is smaller than theoretical value.
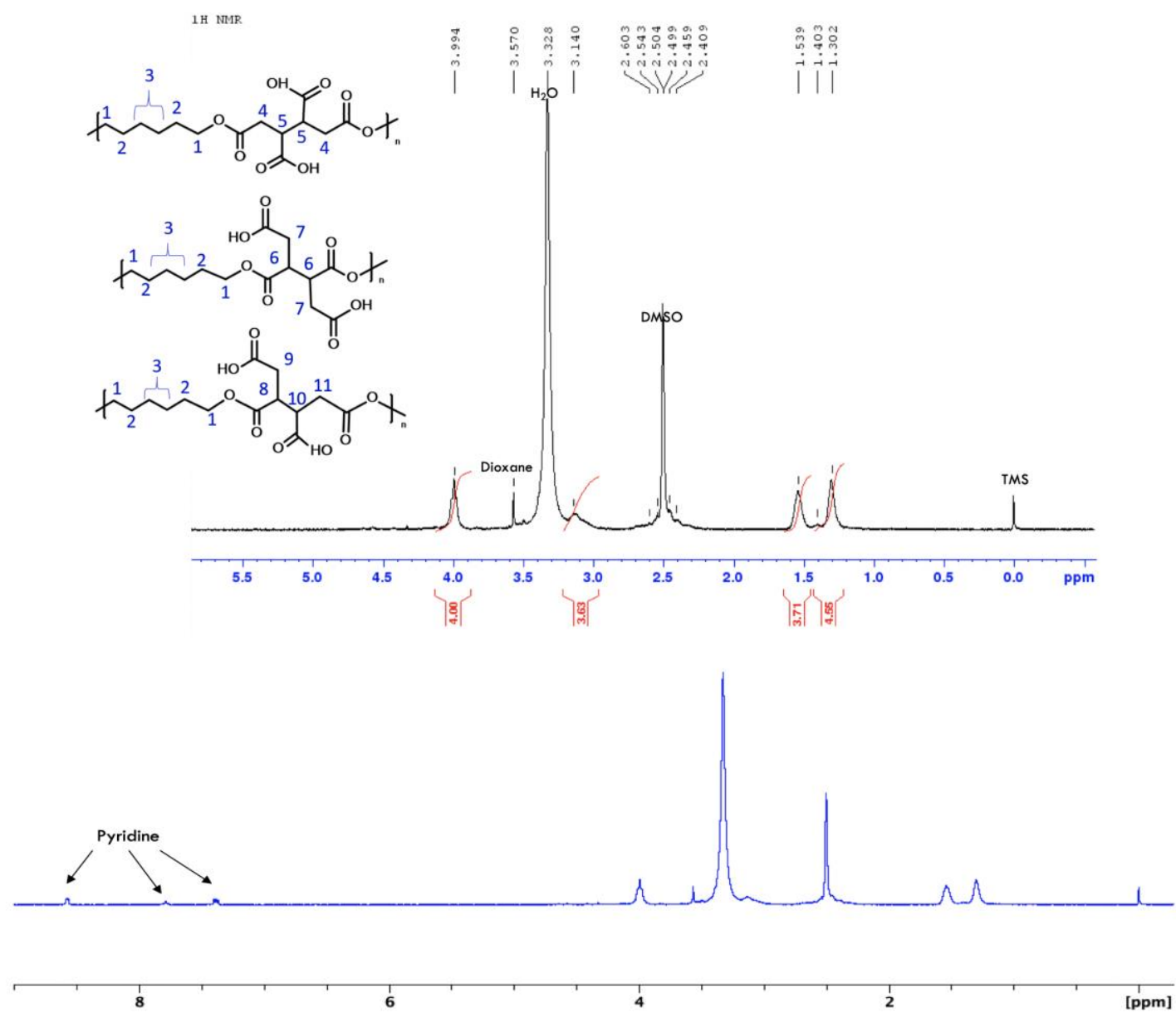

Figure S1. ${ }^{1} \mathrm{H}$ NMR spectra $\left(360 \mathrm{MHz}, \mathrm{DMSO}-d_{6}\right)$ of PE6BA. Chemical shifts were referenced to TMS at $0 \mathrm{ppm}$. The bottom figure shows the full the spectrum with traces amount of pyridine peaks shown at 8.57, 7.77, $7.38 \mathrm{ppm}$.

${ }^{1} \mathrm{H}$ NMR (360 MHz, DMSO- $d_{6}$ ) $\delta$ (ppm) 3.99 (m, 4H, H-1), 3.14 (br, 6H, H-4, H-5, H-6, H-7, H-8, H-9, H-10 \& H11) 1.539 (m, 4H, H-2), 1.302 (m, 4H, H-3). 

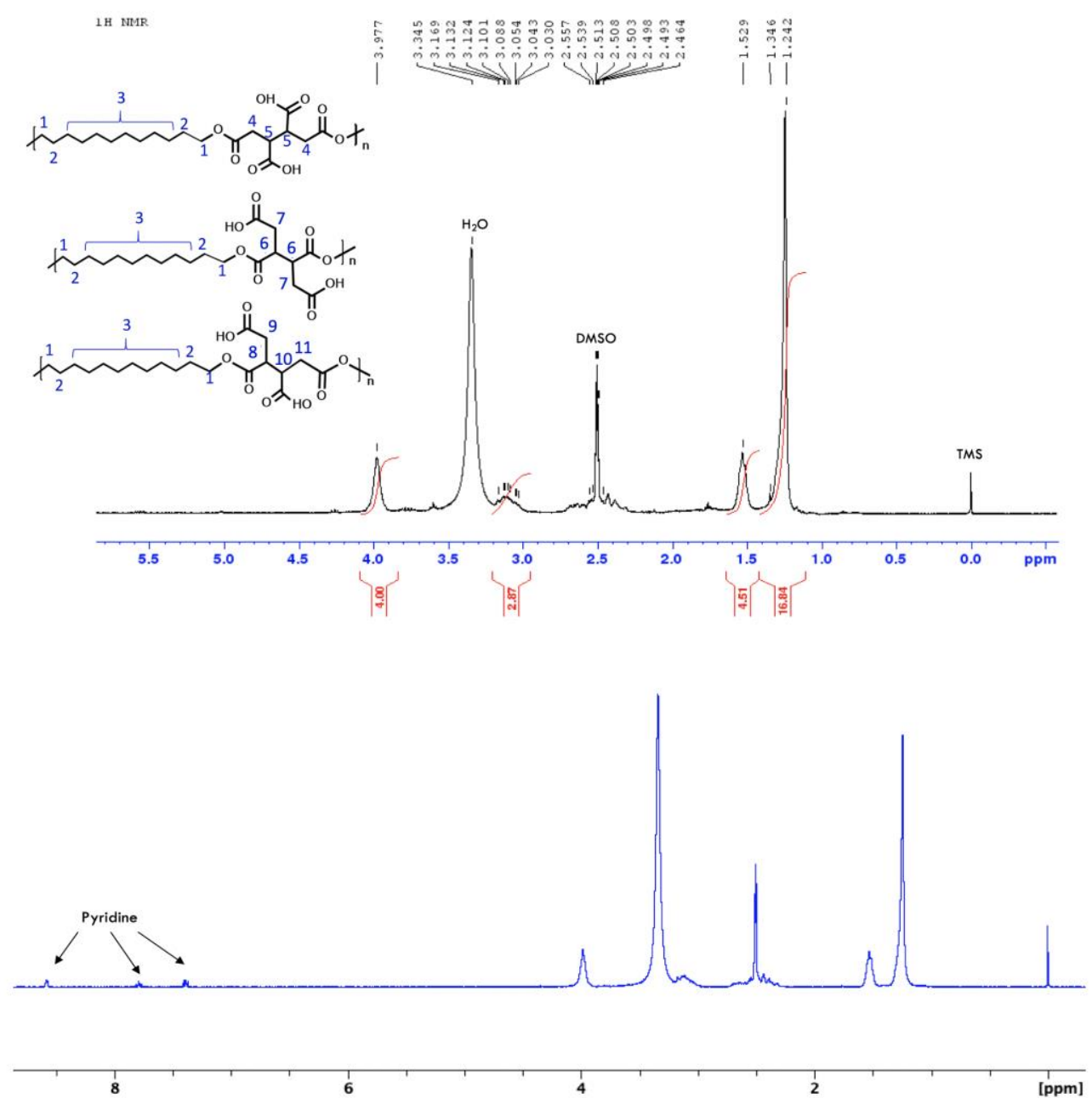

Figure S2. ${ }^{1} \mathrm{H}$ NMR spectra $\left(360 \mathrm{MHz}, \mathrm{DMSO}-d_{6}\right)$ of PE12BA. Chemical shifts were referenced to TMS at $0 \mathrm{ppm}$. The bottom figure shows the full the spectrum with traces amount of pyridine peaks shown at $8.57,7.79,7.38 \mathrm{ppm}$.

${ }^{1} \mathrm{H}$ NMR (360 MHz, DMSO- $d_{6}$ ) $\delta$ (ppm) 3.98 (m, 4H, H-1), 3.03-3.17 (br, 6H, H-4, H-5, H-6, H-7, H-8, H-9, H-10 \& H11), 1.53 (m, 4H, H-2), 1.302 (m, 16H, H-3). 


\section{GPC chromatograms}
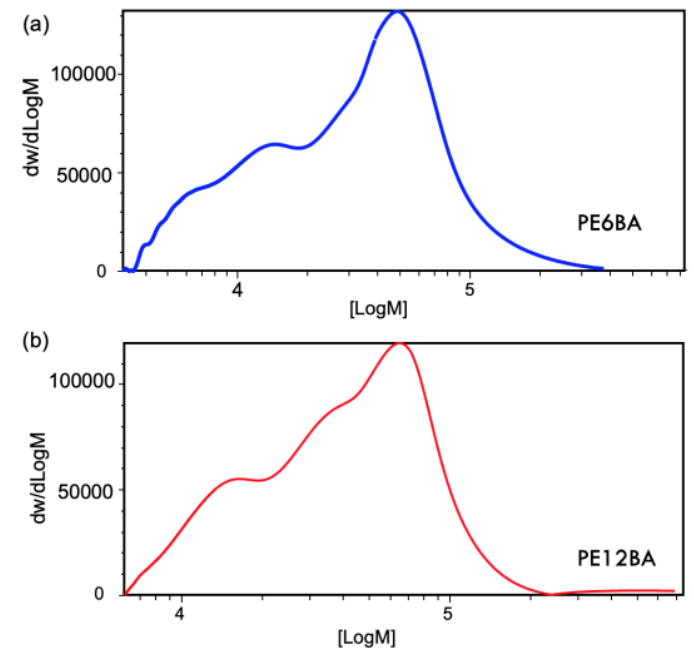

Figure S3. GPC chromatograms of (a) PE6BA and (b) PE12BA polymer.

\section{Elemental Analysis Results}

Table S1. Elemental Analysis Results.

\begin{tabular}{llll}
\hline Polymers & $\mathrm{C}(\%)$ & $\mathrm{H}(\%)$ & $\mathrm{Li}(\%)$ \\
\hline PE6BA & 51.28 & 5.98 & -- \\
PE6BA-14Li & 53.36 & 6.21 & 0.31 \\
PE6BA-36Li & 52.91 & 6.10 & 0.67 \\
PE6BA-65Li & 52.83 & 5.87 & 1.22 \\
PE6BA-82Li & 52.61 & 5.75 & -- \\
\hline PE12BA & 63.23 & 7.52 & 0.31 \\
PE12BA-21Li & 60.87 & 7.87 & 0.44 \\
PE12BA-30Li & 59.82 & 7.82 & 0.74 \\
PE12BA-50Li & 59.64 & 7.72 & 1.17 \\
PE12BA-79Li & 58.21 & 7.53 & \\
\hline
\end{tabular}




\section{FTIR Spectra}

(a)

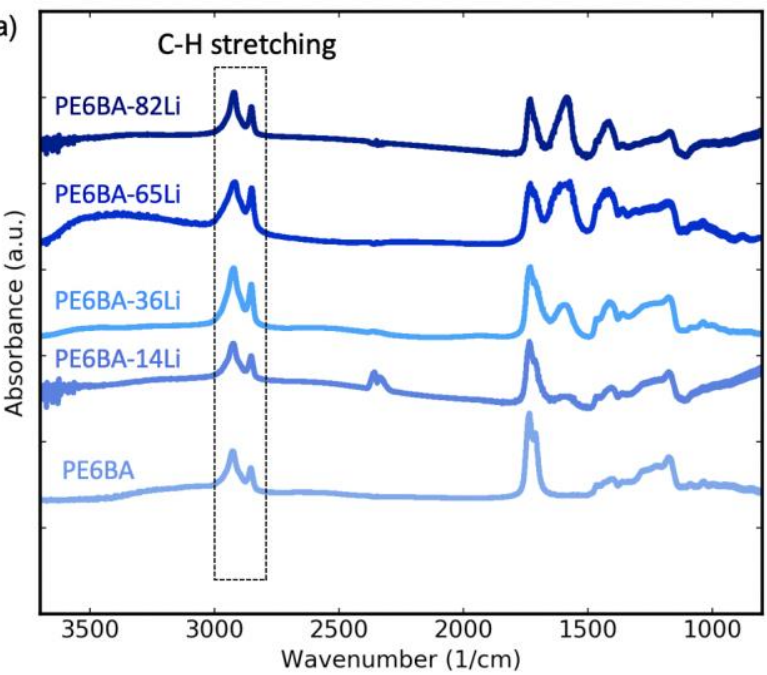

(b)

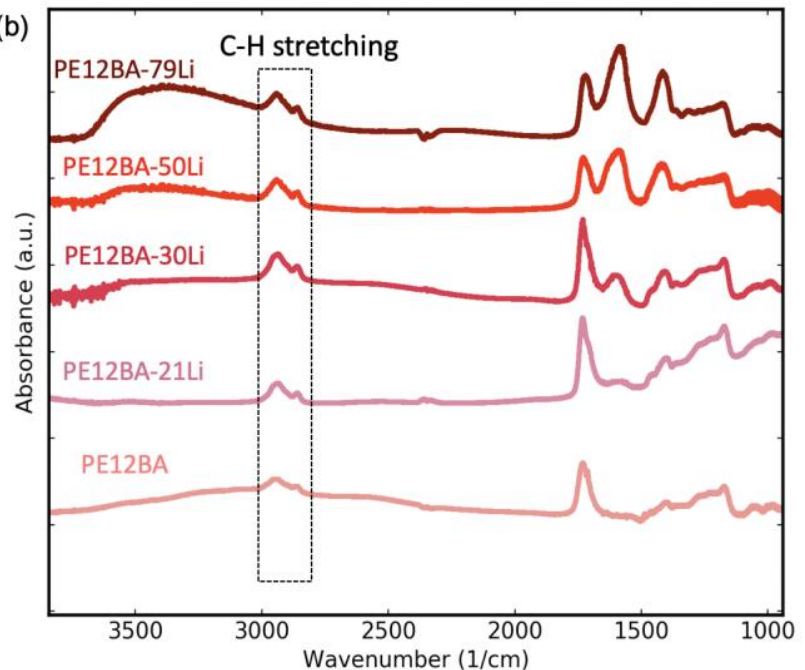

Figure S4. FTIR spectra of (a) PE6BA and (b) PE12BA polymer.

\section{DSC Thermogram}
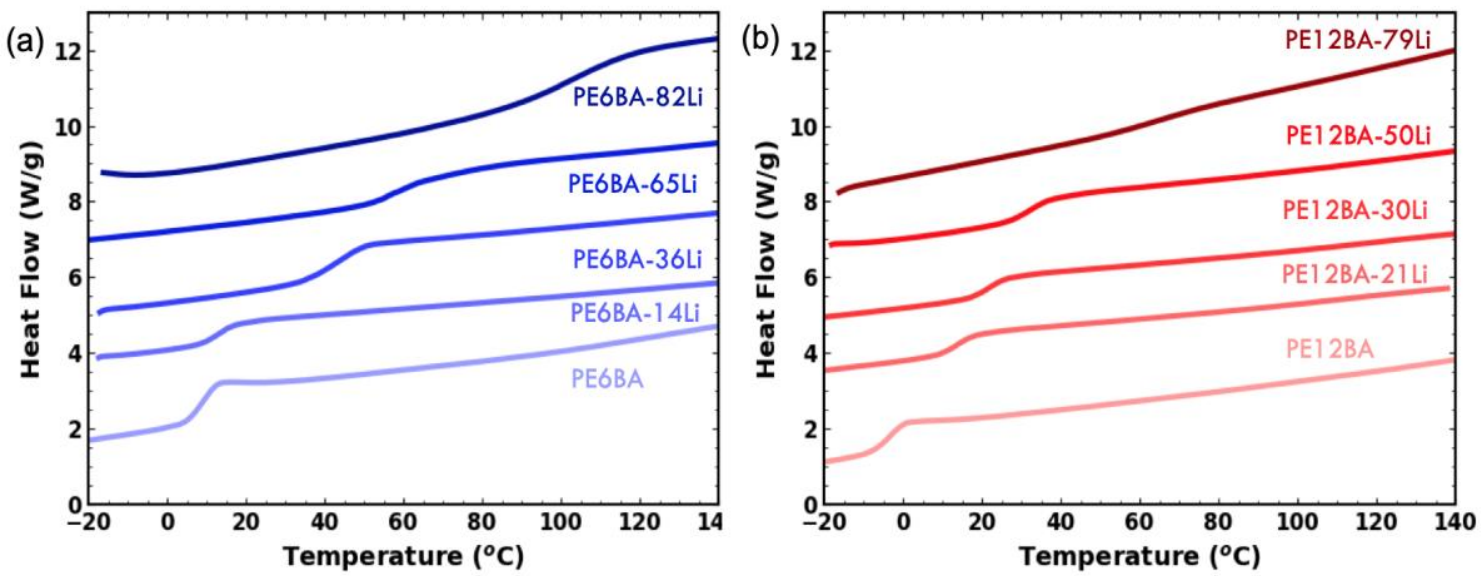

Figure S5. DSC thermograms of (a) PE6BA and (b) PE12BA polymers during the second heating at $10^{\circ} \mathrm{C} / \mathrm{min}$. 
Fitting of the $\mathbf{X}$-ray scattering profiles
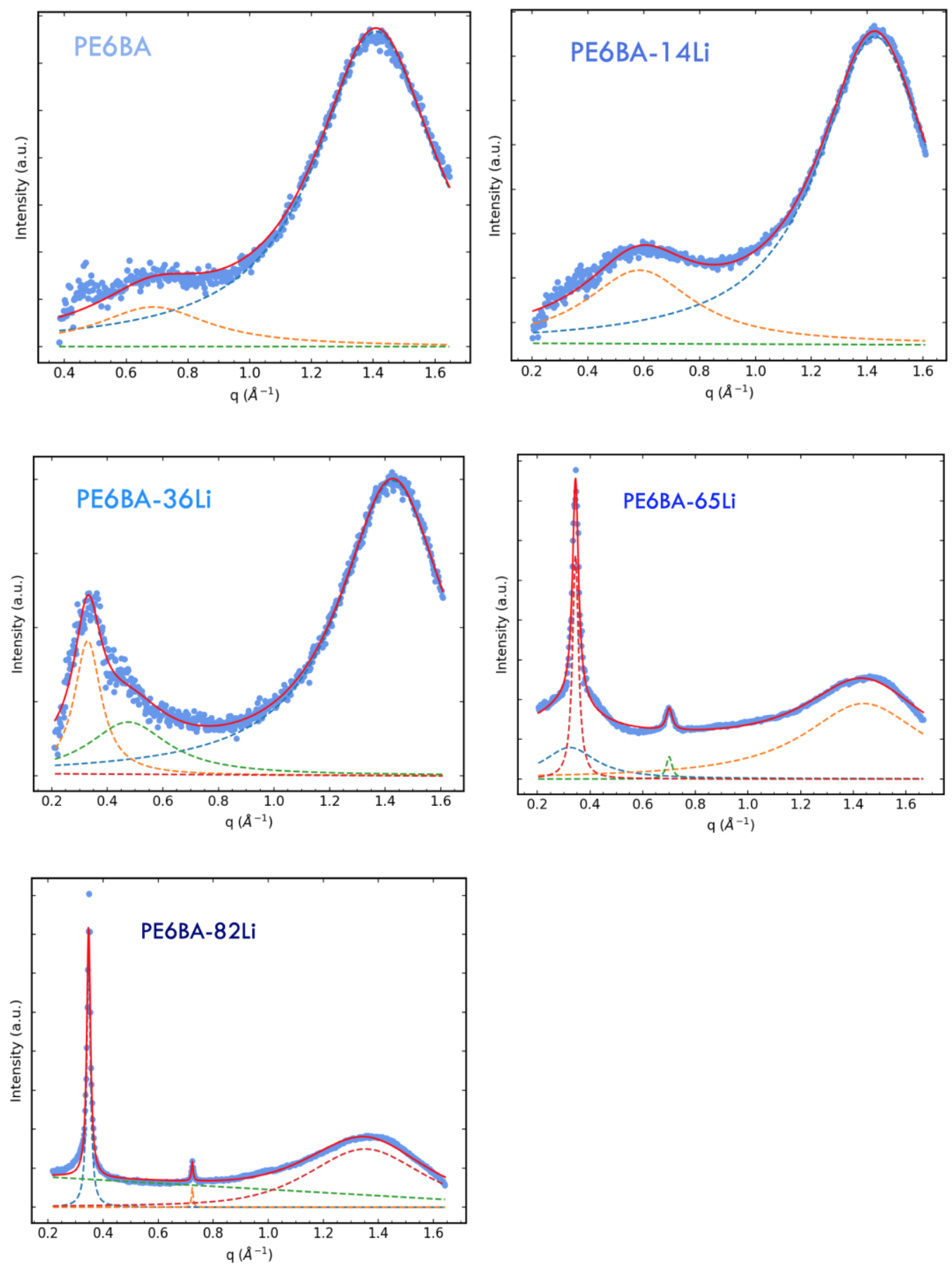

Figure S6. Fitting of the X-ray scattering profiles (light blue dots) of PE6BA polymers before and after neutralization with pseudo-Voigt functions and a linear background (color dashed lines). The total fits are shown in red solid lines. 

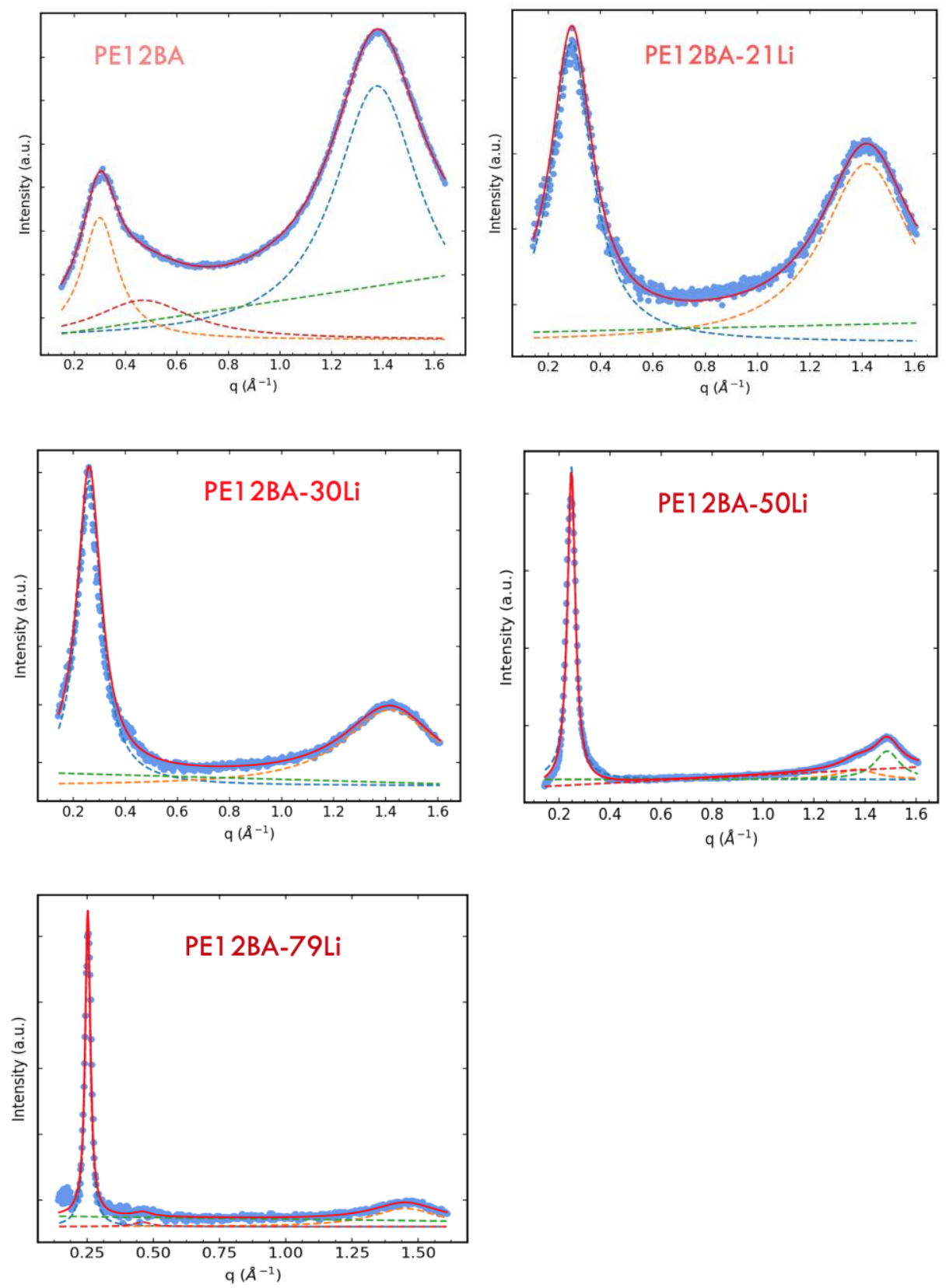

Figure S7. Fitting of the X-ray scattering profiles (light blue dots) of PE12BA polymers before and after neutralization with pseudo-Voigt functions and a linear background (color dashed lines). The total fits are shown in red solid lines. 
Table S2. Fitting parameters of the $1^{\text {st }}$ order ionomer peak $\left(q^{*}\right)$ in PE6BA and PE12BA nearly precise polymers.

\begin{tabular}{ccc}
\hline Polymers & $q^{*}\left(\AA^{-1}\right)$ & FWHM $\left(\AA^{-1}\right)$ \\
\hline PE6BA & 0.687 & 0.441 \\
PE6BA-14Li & 0.584 & 0.470 \\
PE6BA-36Li & 0.329 & 0.118 \\
PE6BA-65Li & 0.344 & 0.027 \\
PE6BA-82Li & 0.347 & 0.016 \\
\hline PE12BA & 0.300 & 0.168 \\
PE12BA-21Li & 0.290 & 0.189 \\
PE12BA-30Li & 0.261 & 0.112 \\
PE12BA-50Li & 0.247 & 0.036 \\
PE12BA-79Li & 0.252 & 0.023 \\
\hline
\end{tabular}




\section{Electrochemical Impedance Spectroscopy (EIS) data}

Figure S7 shows a Nyquist plot of the impedance data obtained from PE6BA-82Li ionomer at $385 \mathrm{~K}$. As commonly observed in ion-conducting polymer electrolytes, there is a semicircle at high frequency range, and a capacitive tail at low frequencies. A parallel combination of resistor $\left(\mathrm{R}_{\mathrm{b}}\right)$, and a constant phase element (CPE2) accounts for the semicircle resulting from the bulk resistance and the geometry capacity of the electrolyte. The low frequency straight tail after the semicircle can be explained with CPE1 corresponding to the double layer capacity of an inhomogeneous electrode surface. ${ }^{1}$

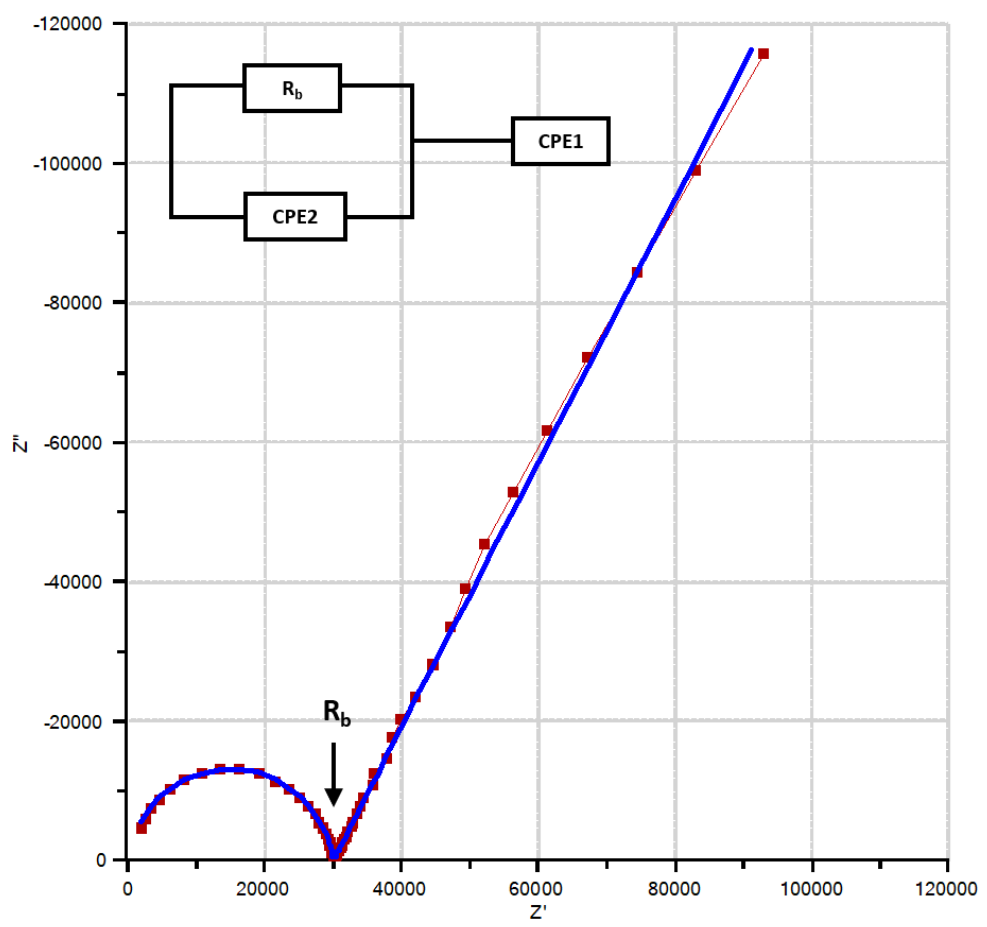

Figure S8. Nyquist impedance plot $\left(Z^{\prime \prime} v s Z^{\prime}\right)$ of PE6BA-82Li at $385 \mathrm{~K}$ for a frequency range of $1 \mathrm{MHz}$ to $0.1 \mathrm{~Hz}$. Red squares and solid line correspond to the experimental data and the blue solid line shows the fitting with equivalent circuit shown in the inset. 
Fitting parameters for ionic conductivity data

Table S3. VFT or Arrhenius fitting parameters for ionic conductivity

\begin{tabular}{c|ccc|cc}
\hline \multirow{2}{*}{ Polymers } & \multicolumn{3}{|c|}{ VFT } & \multicolumn{3}{c}{ Arrhenius } \\
& $\log \sigma_{\infty}(\mathrm{S} / \mathrm{cm})$ & $\mathrm{D}$ & $\mathrm{T}_{0}(\mathrm{~K})$ & $\log \sigma_{0}(\mathrm{~S} / \mathrm{cm})$ & $\mathrm{E}_{\mathrm{a}}(\mathrm{kJ} / \mathrm{mol})$ \\
\hline PE6BA-82Li & -- & -- & -- & 8.2 & 46.8 \\
\hline PE6BA-65Li & -- & -- & -- & 8.4 & 46.1 \\
\hline PE6BA-36Li & -1.1 & 3.1 & 239.3 & -- & -- \\
\hline PE6BA-14Li & -0.3 & 3.7 & 240.6 & -- & 45.9 \\
\hline PE12BA-79Li & -- & -- & -- & 7.1 & -- \\
\hline PE12BA-50Li & -1.8 & 2.9 & 245.4 & -- & -- \\
\hline PE12BA-30Li & 2.9 & 12.4 & 171.0 & -- & - \\
\hline PE12BA-21Li & 2.1 & 14.1 & 162.4 & -- & - \\
\hline
\end{tabular}

\section{References}

(1) Rubinson, J. F.; Kayinamura, Y. P. Charge Transport in Conducting Polymers: Insights from Impedance Spectroscopy. Chem. Soc. Rev. 2009, 38 3339-3347. 